\title{
Absence of relationships between selected human factors and natural infectivity of Plasmodium falciparum to mosquitoes in an area of high transmission
}

\author{
H. HAJI I.2, T. SMITH ${ }^{3 *}$, J. D. CHARLWOOD ${ }^{1}$ and J. H. MEUWISSEN ${ }^{4}$ \\ ${ }^{1}$ Ifakara Centre, PO Box 53, Ifakara, Tanzania \\ ${ }^{2}$ Ministry of Health, PO Box 236, Zanzibar, Tanzania \\ ${ }^{3}$ Swiss Tropical Institute, PO Box 4002, Basel, Switzerland \\ ${ }^{4}$ Department of Medical Microbiology, University of Nijmegen, PO Box 9101, 6500 HB, The Netherlands
}

(Received 5 February 1996; revised 22 May 1996; accepted 22 May 1996)

SUMMARY

The effects of sex, age of the human host, patency of asexual and sexual stages and seasonality on infectiousness of Plasmodium falciparum to mosquitoes were investigated in a rural village in southern Tanzania between 1992 and 1994. Villagers from randomized subgroups of households were surveyed for malaria parasites. Gametocyte and trophozoite prevalences were age dependent and fluctuated without any clear pattern of seasonality. A sample of 107 participants, selected to include an excess of gametocyte carriers, slept under bednets with holes cut into the sides for 3 weeks. A total of 3837 Anopheles gambiae s.l. and 5403 A. funestus recovered from these bednets, was examined for all oocysts 5-7 days after feeding or for oocysts less than $17.5 \mu \mathrm{m}$ in diameter $2-3$ days after feeding. Additional blood slides from participants were taken twice weekly. The 5-7 day oocyst rates were $12.1 \%$ in $A$. gambiae s.1. and $10.9 \%$ in $A$. funestus and $2-3$ day rates were 3.6 and $4.9 \%$, respectively. The higher rates using the former method were attributed to previous infection. There were strong correlations in the levels of infection in both vectors when they fed on the same hosts. However, patent gametocytaemia was only weakly associated with the development of oocysts in the mosquito. Infectiousness was not related to host age, sex, or the season.

Key words: malaria, transmission, Tanzania, Anopheles gambiae, Anopheles funestus.

\section{INTRODUCTION}

Malaria transmission to the vector is a complex process, influenced by parasite, host, vector and environmental factors (Dearsly, Sinden \& Self, 1990).

The objective of most field studies of host-vector transmission of malaria has been to assess the overall infectious reservoir in man for mosquitoes rather than to identify the host factors affecting it (Draper, 1953; Muirhead-Thomson, 1954; Muirhead-Thomson \& Mercier, 1952; Graves et al. 1988, 1990; GamageMendis et al. 1991; Githeko et al. 1992; Tchuinkam et al. 1993; Charlwood et al. 1995a,b). The potential development of transmission-blocking vaccines has recently stimulated the study of factors affecting host-vector transmission. Although much progress has been made in the laboratory there is still need for studies on the factors affecting parasite transmission to the vectors in the field (Meuwissen, 1990).

* Corresponding author. Department of Public Health and Epidemiology, Swiss Tropical Institute, PO Box CH-4002 Basel, Switzerland. Tel: +41612848273 . Fax: +41612717951. E-mail: tomsmith@iso.iso.unibas.ch.
The present study assesses the influence of parasite and host factors on the development of the parasite in naturally infected mosquitoes in a Tanzanian village. Engorged mosquitoes were collected from bed net traps placed over known hosts and infections of Plasmodium falciparum in the local mosquitoes were detected by subsequent microscopical examination of the mosquito midgut for oocysts. The effects of host malariological status (parasite prevalence and density), age and the season on infectivity to the local vectors were determined.

\section{MATERIALS AND METHODS}

\section{Study site}

The study was conducted between May 1992-July 1993 and February-December 1994 in the village of Kisegese, southern Tanzania. This is an expanding farming settlement of approximately 100 households $6 \mathrm{~km}$ to the west of Namawala, described by Smith et al. (1993) and Charlwood et al. (1995a). The population is highly mobile and seasonal. A sizeable number are immigrants from Iringa and from the far southern regions of Mbeya and Songea, regions that have low malaria transmission due to high altitudes. 
The main occupation is cultivation of non-irrigated rice and corn. There are 2 rainy seasons. The short rains occur in December-January, when crops are planted, and the long rains from March to May, when there is often extensive flooding. June and July are the cool season when crops are harvested. This is followed by a long dry season extending to November, when temperatures rise and there is extensive burning of arable land and bush.

Plasmodium falciparum malaria in the area is highly endemic; most of the population are infected at any one time (Smith et al. 1993) and transmission occurs throughout the year. Anopheles gambiae s.l. and $A$. funestus are the predominant vectors (Smith et al. 1993), both occurring for most of the year. The $A$. funestus population declines during the dry season (October-December) but $A$. gambiae s.l. continues to breed in isolated pockets along the receding Ruipa River, which crosses the northern part of the village.

\section{Initial blood surveys and recruitment}

A list of households in the village was obtained from the previous work of the Kilombero Malaria Project. Households were divided at random into subgroups of 10-household units. Villagers in each subgroup were surveyed in rotation, at approximately monthly intervals, for malaria parasites and for mosquito collection from selected individuals.

Each selected household was visited and each resident was registered and assigned a unique identification number. Blood was obtained by finger prick from consenting individuals. For children, consent was obtained from their parents or guardians. All age groups above 3 months of age were sampled. Thick blood films were prepared from $20 \mu \mathrm{l}$ of blood, drawn by non-heparinized capillary tube and spread onto microscope slides. About $2 \mathrm{ml}$ of blood was squeezed into vacutainers (without a separation plug) maintained in a cool condition in a thermal bag or box containing cooling packs. The sera were processed at the field laboratory (in Namawala) and stored temporarily in the freezer chamber of a kerosene-operated refrigerator at approximately $-10^{\circ} \mathrm{C}$. The next day the sera were transported to the main laboratory in Ifakara and stored at $-80^{\circ} \mathrm{C}$.

When all households had been included in the screening surveys, the households were rerandomized into new subgroups and subsequently re-sampled.

\section{Examination of thick films for malaria parasites}

Thick blood films were stained with Giemsa. Following an initial screening of 100 fields in Namawala, 200 fields were examined under oil immersion $(\times 100)$ in the laboratory in Ifakara. Malaria parasites were identified to species and densities of asexual stages and gametocytes of $P$. falciparum/1000 leucocytes determined. Densities and prevalences of other species were also determined and will be reported elsewhere.

\section{Net-with-hole experiments}

Traps consisting of cone-shaped mosquito nets with 2-4 juxtaposed holes of about $6 \mathrm{~cm}$ diameter halfway up the sides were used for mosquito collection.

People with patent gametocytes (selected on the basis of the initial field reading of the blood slides) and a sample of the remaining population slept alone, at their usual sleeping place, under the nets from Sunday to Thursday for 3 weeks. Children below 2 years of age and individuals who were not willing or able to sleep alone under the nets, were excluded from this phase of the study.

Mosquitoes were collected, each morning, into paper cups and transported to the field laboratory where they were provided with a $10 \%$ sugar solution and kept at ambient temperature and humidity until they were dissected.

Thick blood films were taken from participants up to twice a week on separate days. At the end of each replicate participants were given a new intact net.

\section{Mid-gut examinations of field-caught mosquitoes for oocysts}

Two different methods were used at different times to assess mosquitoes for oocysts.

Method I (1992-93). Midguts from mosquitoes that had been held for 5-7 days in the field laboratory were dissected in normal saline, transferred into a drop of $2 \%$ mercuro-chrome (mebromine) solution in water on a slide for staining, covered with a coverglass and immediately examined using a dry $\times 40$ object lens with a compound microscope.

Method II (1994). Mosquitoes were held until digestion of the bloodmeal had been completed (which varied between 2 and 3 days according to temperature) and midguts, all collected from mosquitoes on a single day from one specified net, dissected in $2 \%$ mebromine solution and transferred into a $4 \%$ phosphate-buffered formaldehyde solution in $2 \mathrm{ml}$ plastic vials for preservation. Up to 40 midguts were stored per vial. This method enabled batch processing of mosquitoes. Preserved midguts, which remained in good condition for more than 2 years, were mounted in the $4 \%$ phosphate-buffered formaldehyde and examined using the same microscopy technique as for Method I. The presence of very small oocysts was sometimes confirmed using an immersion object lens. Oocysts from preserved stomachs were measured to an accuracy of $0.3 \mu \mathrm{m}$ using a calibrated ocular graticule on the compound microscope. Only oocysts less than $17 \cdot 5 \mu \mathrm{m}$ in 
Table 1. Age dependence of parasitaemia at screening surveys

\begin{tabular}{lllll}
\hline \hline $\begin{array}{l}\text { Age } \\
\text { (years) }\end{array}$ & $\begin{array}{l}\text { No. of } \\
\text { slides }\end{array}$ & $\begin{array}{l}\text { Trophozoite } \\
\text { prevalence }\end{array}$ & $\begin{array}{l}\text { Gametocyte } \\
\text { prevalence }\end{array}$ & $\begin{array}{l}\text { Geometric mean } \\
\text { gametocyte density* } \\
(95 \% \text { CL) }\end{array}$ \\
\hline $0-4$ & 141 & $0 \cdot 837$ & $0 \cdot 220$ & $29 \cdot 7(20 \cdot 7,42 \cdot 5)$ \\
$5-9$ & 169 & $0 \cdot 787$ & $0 \cdot 101$ & $19 \cdot 4(13 \cdot 4,28 \cdot 3)$ \\
$10-14$ & 141 & $0 \cdot 730$ & $0 \cdot 028$ & $25 \cdot 8(22 \cdot 4,29 \cdot 7)$ \\
$15-19$ & 91 & $0 \cdot 593$ & $0 \cdot 077$ & $12 \cdot 1(8 \cdot 3,17 \cdot 7)$ \\
$20-29$ & 127 & $0 \cdot 449$ & $0 \cdot 110$ & $16 \cdot 9(12 \cdot 6,22 \cdot 8)$ \\
$30-39$ & 109 & 0.367 & $0 \cdot 064$ & $30 \cdot 5(11 \cdot 5,81 \cdot 3)$ \\
40 or more & 120 & $0 \cdot 333$ & 0.042 & $26 \cdot 8(16 \cdot 4,43 \cdot 7)$ \\
All ages & 898 & 0.607 & 0.095 & $23 \cdot 0(19 \cdot 0,27 \cdot 8)$ \\
\hline \hline
\end{tabular}

* Gametocytes $/ \mu 1$, gametocyte positive slides only.

Table 2. Characteristics of 107 individuals included in the study

\begin{tabular}{|c|c|c|}
\hline & Mean & S.D. \\
\hline \multicolumn{3}{|l|}{ No. of mosquitoes tested } \\
\hline A. funestus & $30 \cdot 5$ & $64 \cdot 4$ \\
\hline A. gambiae s.1. & $36 \cdot 0$ & 39.9 \\
\hline \multicolumn{3}{|l|}{$\begin{array}{l}\text { Percentage of mosquitoes } \\
\text { positive for oocysts }\end{array}$} \\
\hline A. funestus* & $8 \cdot 0$ & $14 \cdot 2$ \\
\hline A. gambiae s.l.* & $7 \cdot 6$ & $13 \cdot 3$ \\
\hline No. of blood slides $\uparrow$ & $4 \cdot 3$ & $2 \cdot 9$ \\
\hline $\begin{array}{l}\% \text { slides positive for } \\
P \text {. falciparum gametocytes }\end{array}$ & $14 \cdot 7$ & $23 \cdot 7$ \\
\hline $\begin{array}{l}\% \text { slides positive for } \\
P \text {. falciparum trophozoites }\end{array}$ & $66 \cdot 7$ & $35 \cdot 7$ \\
\hline $\begin{array}{l}\text { Density of } P . \text { falciparum } \\
\text { gametocytes }(/ \mu \mathrm{l})\end{array}$ & $9 \cdot 8$ & $16 \cdot 1$ \\
\hline $\begin{array}{c}\text { Density of } P \text {. falciparum } \\
\text { trophozoites }(/ \mu \mathrm{l})\end{array}$ & 1296 & 2852 \\
\hline Age last birthday (years) & $15 \cdot 2$ & $12 \cdot 7$ \\
\hline
\end{tabular}

* A. funestus for oocyst dissections were not collected from 16 individuals, and $A$. gambiae s.l. were not collected from 9 individuals.

+ In the cases of 2 individuals, no blood slides were available.

diameter, considered to be those from the most recent feed (Haji et al. 1996), were recorded. In that study we estimated that about $22 \%$ of oocysts from the latest feed in A. gambiae s.l. and $20 \%$ in $A$. funestus would exceed this size cutoff but that the use of a higher cutoff would result in unacceptable rates of contamination with older oocysts.

\section{RESULTS}

A total of 898 individuals was screened in the surveys. Table 1 shows the gametocyte rate and the general $P$. falciparum infection rate by age. Both decreased markedly with age, but gametocyte densities (among individuals with gametocytes) did not show any clear age dependence. Of the survey participants 105, and an additional 2 individuals for whom blood slide results were not available, were

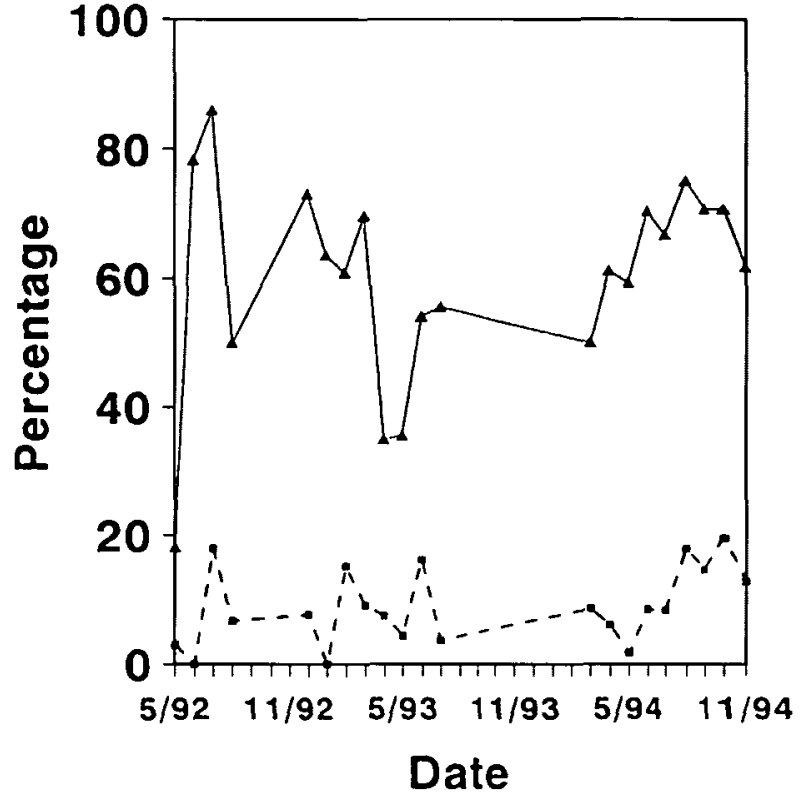

Fig. 1. Parasite prevalence in screening surveys by month. (---) Plasmodium falciparum gametocytes; (A- $\mathbf{\Delta})$ P. falciparum trophozoites.

selected for inclusion in the net-with-hole experiments. Of these participants $51(48 \%)$ were female. Averages of other characteristics of the 107 participants are shown in Table 2.

Fifteen $(14 \%)$ of the participants were gametocytaemic at the initial screening compared with 85 $(9.5 \%)$ of the overall population $\left(\chi_{1}^{2}=2 \cdot 5, P=0.1\right)$. Because gametocytaemia was more frequent in younger individuals, even though children of under 2 years of age were excluded from the study, the selection procedure resulted in a sample of individuals who were younger (mean age $15 \cdot 3$ years, S.D. $=12.8$ years) than the overall screened population (mean 19.6 years, S.D. $=16.5$ years). However, the proportion with $P$. falciparum trophozoites in the selected net with hole sleeper individuals $(68 \%)$ was similar to that in the overall screened population $(61 \%)$. Despite the deliberate enrichment of the sample with individuals with gametocytes, within any one age group those with trophozoites were no 
Table 3. Comparison of methods of mid-gut examination

\begin{tabular}{lcc}
\hline \hline & Method I & Method II \\
\hline No. of individuals & 34 & 73 \\
Total $A$. funestus examined & 1905 & 3498 \\
Total $A$. gambiae s.1. & 1039 & 2812 \\
Percentage of $A$. funestus & 10.9 & 4.9 \\
oocyst positive & $12 \cdot 1$ & 3.6 \\
Percentage of $A$.gambiae & & $1.7(1 \cdot 5,1 \cdot 9)$ \\
s.l. oocyst positive & $2 \cdot 7(2 \cdot 3,3 \cdot 2)$ & $2 \cdot 0(1 \cdot 7,2 \cdot 4)$ \\
Geom. mean oocyst density & $2 \cdot 4(2 \cdot 1,2 \cdot 9)$ & \\
Geom. mean oocyst density & & \\
(95\% CI) $A$. gambiae s.l.* & & \\
*Oocyst positive mosquitoes only. & & \\
\hline
\end{tabular}

more likely to be selected than those without (Mantel-Haenszel estimate of the risk ratio, 1.0; $95 \%$ C.I. $0 \cdot 7-1 \cdot 6)$.

The parasitological picture in the total of 359 subsequent slides from the enrolled individuals continued to differ from that of the overall population with a gametocyte rate of $17 \%$ and a trophozoite rate of $68 \%$, similar to the pattern at enrolment. However, only 3 individuals had gametocytes throughout their follow up periods. Thus, despite continual changes in status, the selected group continued to have a greater chance of gametocytaemia than the general population. This was probably largely due to the selected group being younger than the overall population.

Figure 1 shows how the gametocyte and trophozoite rates in the screening surveys varied during the whole period. Trophozoite and gametocyte rates showed similar irregular patterns of change over time.

Mosquitoes from a total of $34(32 \%)$ of the participants were processed using Method I and 73 $(68 \%$ ) using Method II. Oocyst rates detected by Method I were much higher than by Method II (Table 3) although average oocyst densities especially in $A$. gambiae s.l., were similar using the two methods. The oocyst rate in Method I was similar in both species (Table $3 ; \chi_{1}^{2}=1 \cdot 1, P=0.3$ ) but was lower in A.gambiae s.l. than in A. funestus (Table 3; $\chi_{1}^{2}=6.9, P=0.009$ ) in Method II. Distributions of oocyst numbers in infected mosquitoes were highly skewed, with a mode of 1 for both species and both methods. A total of 84 individuals provided batches of mosquitoes with a mixture of $A$. gambiae s.l. and $A$. funestus. The Spearman correlation coefficient between the mean oocyst rates for the two species for these individuals was $0.29(P=0.007)$. The Spearman correlation between the mean oocyst densities was $0.82(P=0.0001)$. Similar correlations were obtained when this analysis was carried out separately for the two different methods of oocyst scoring.
Table 4 gives the correlations between malariological status of individual hosts and oocyst rates for the two oocyst scoring techniques and the two vector species separately, using the average of all slides for an individual to indicate the malariological status. Using Method II, oocyst rates in $A$. funestus and oocyst densities in $A$. gambiae s.l. were significantly correlated with the prevalence of $P$. falciparum gametocytes. In neither species was there a statistically significant relationship between oocysts and host gametocyte or trophozoite densities (Table 4). There was a statistically significant, though weak, association between gametocyte rate and mean oocyst density in $A$. gambiae, but not in $A$. funestus. Since the table contains a large number of correlations, this relationship may have simply arisen by chance. The sex of the host did not appear to affect infectiousness (data not shown) nor were there significant correlations with age (Table 4).

Out of 39 individuals without detectable gametocytes throughout their investigation periods 29 were infectious to mosquitoes as assessed by Method II. By this method $51 / 1673(3.0 \%)$ of $A$. gambiae s.l. and $61 / 1571(3.9 \%)$ of $A$. funestus feeding on these 29 individuals had oocysts. Of these individuals 7 had no evidence of any stage of $P$. falciparum on any of their blood slides, even so 5 of them infected mosquitoes. Of the individuals assessed by Method II only 1 had patent gametocytaemia on all blood slides (a total of 7). One of $43 A$. funestus caught after feeding on this individual had small oocysts. No $A$. gambiae s.l. were caught feeding on this individual.

An alternative to considering the average malariological status of the individual over the whole period, is to correlate the malariological status as determined by a single slide with infectivity to mosquitoes biting during the succeeding night. A total of 140 pairs of slides and subsequent mosquito collections evaluated using Method II was available for this analysis. Table 5 gives the Spearman correlations between malariological status (and age) and the oocyst rates. There are no statistically significant correlations. 
Table 4. Relationships of infectiousness over the whole follow-up period with host characteristics

(All quoted correlation coefficients are Spearman correlations. The figures in parentheses are $\boldsymbol{P}$-values. The Spearman correlation between oocyst rates in $A$. gambiae and $A$. funestus was $0.29(P=0.007)$, based on 84 individuals from whom mosquitoes of both species were analysed. The correlation between mean oocyst densities in the two species was 0.82 $(P=0.0001)$ (data of both methods aggregated).)

\begin{tabular}{|c|c|c|c|c|c|c|}
\hline & \multicolumn{3}{|c|}{ Anopheles funestus } & \multicolumn{3}{|c|}{ Anopheles gambiae s.1. } \\
\hline & \multicolumn{2}{|c|}{ Method } & \multirow[b]{2}{*}{ Overall } & \multicolumn{2}{|l|}{ Method } & \multirow[b]{2}{*}{ Overall } \\
\hline & I & II & & I & II & \\
\hline \multicolumn{7}{|c|}{ (a) Spearman correlations with oocyst rates } \\
\hline Gametocyte rate & $\begin{array}{r}0 \cdot 21 \\
(0 \cdot 3)\end{array}$ & $\begin{array}{c}0.26 \\
(0.046)\end{array}$ & $\begin{array}{c}0 \cdot 16 \\
(0 \cdot 1)\end{array}$ & $\begin{array}{c}0 \cdot 19 \\
(0 \cdot 3)\end{array}$ & $\begin{array}{c}-0.03 \\
(0 \cdot 8)\end{array}$ & $\begin{array}{c}-0.007 \\
(0.9)\end{array}$ \\
\hline Density of gametocytes* & $\begin{array}{c}0 \cdot 45 \\
(0 \cdot 3)\end{array}$ & $\begin{array}{c}0.25 \\
(0.19)\end{array}$ & $\begin{array}{c}0.28 \\
(0.09)\end{array}$ & $\begin{array}{r}-0 \cdot 23 \\
(0 \cdot 6)\end{array}$ & $\begin{array}{c}-0.09 \\
(0.6)\end{array}$ & $\begin{array}{c}-0.06 \\
(0.7)\end{array}$ \\
\hline Trophozoite rate & $\begin{array}{r}-0.06 \\
(0.8)\end{array}$ & $\begin{array}{c}0.02 \\
(0.9)\end{array}$ & $\begin{array}{c}-0.007 \\
(0.9)\end{array}$ & $\begin{array}{r}-0.05 \\
(0.8)\end{array}$ & $\begin{array}{c}0 \cdot 11 \\
(0 \cdot 3)\end{array}$ & $\begin{array}{c}0.09 \\
(0.4)\end{array}$ \\
\hline Density of trophozoites* & $\begin{array}{r}-0.14 \\
(0.5)\end{array}$ & $\begin{array}{c}0.002 \\
(0.99)\end{array}$ & $\begin{array}{c}0.01 \\
(0.9)\end{array}$ & $\begin{array}{r}0 \cdot 30 \\
(0.2)\end{array}$ & $\begin{array}{c}0.004 \\
(0.97)\end{array}$ & $\begin{array}{c}0 \cdot 18 \\
(0 \cdot 1)\end{array}$ \\
\hline Age & $\begin{array}{c}-0.08 \\
(0.7)\end{array}$ & $\begin{array}{c}0.08 \\
(0.5)\end{array}$ & $\begin{array}{c}0.06 \\
(0.6)\end{array}$ & $\begin{array}{r}0.04 \\
(0.8)\end{array}$ & $\begin{array}{c}0.01 \\
(0.9)\end{array}$ & $\begin{array}{r}-0.02 \\
(0.9)\end{array}$ \\
\hline \multicolumn{7}{|c|}{ (b) Spearman correlations with mean oocyst densities } \\
\hline Gametocyte rate & $\begin{array}{r}0 \cdot 17 \\
(0 \cdot 4)\end{array}$ & $\begin{array}{c}0.22 \\
(0.08)\end{array}$ & $\begin{array}{c}0 \cdot 14 \\
(0 \cdot 2)\end{array}$ & $\begin{array}{r}0.31 \\
(0.1)\end{array}$ & $\begin{array}{c}0.24 \\
(0.04)\end{array}$ & $\begin{array}{c}0.24 \\
(0.016)\end{array}$ \\
\hline Density of gametocytes* & $\begin{array}{c}0.51 \\
(0.2)\end{array}$ & $\begin{array}{c}0.29 \\
(0.1)\end{array}$ & $\begin{array}{c}0 \cdot 29 \\
(0 \cdot 08)\end{array}$ & $\begin{array}{c}0.02 \\
(0.95)\end{array}$ & $\begin{array}{c}0 \cdot 28 \\
(0 \cdot 1)\end{array}$ & $\begin{array}{c}0 \cdot 27 \\
(0 \cdot 1)\end{array}$ \\
\hline Trophozoite rate & $\begin{array}{r}-0 \cdot 24 \\
(0 \cdot 2)\end{array}$ & $\begin{array}{r}-0.03 \\
(0.8)\end{array}$ & $\begin{array}{c}-0.06 \\
(0.6)\end{array}$ & $\begin{array}{c}-0.26 \\
(0.2)\end{array}$ & $\begin{array}{c}0.09 \\
(0.4)\end{array}$ & $\begin{array}{c}0.007 \\
(0.9)\end{array}$ \\
\hline Density of trophozoites* & $\begin{array}{r}0.07 \\
(0.7)\end{array}$ & $\begin{array}{c}0.04 \\
(0.8)\end{array}$ & $\begin{array}{c}0.09 \\
(0.4)\end{array}$ & $\begin{array}{c}0.05 \\
(0.8)\end{array}$ & $\begin{array}{c}0 \cdot 20 \\
(0 \cdot 1)\end{array}$ & $\begin{array}{c}0.21 \\
(0.058)\end{array}$ \\
\hline Age & $\begin{array}{r}0.03 \\
(0.9)\end{array}$ & $\begin{array}{c}0 \cdot 10 \\
(0.5)\end{array}$ & $\begin{array}{c}0.08 \\
(0.5)\end{array}$ & $\begin{array}{c}0 \cdot 19 \\
(0 \cdot 3)\end{array}$ & $\begin{array}{r}-0 \cdot 13 \\
(0 \cdot 3)\end{array}$ & $\begin{array}{c}0 \cdot 05 \\
(0 \cdot 6)\end{array}$ \\
\hline
\end{tabular}

* Average density in positive slides. Only individuals with positive slides were included in the analysis.

Table 5. Spearman correlations between slide readings and oocyst rates for mosquitoes caught on the following day and examined by Method II

\begin{tabular}{lcc}
\hline \hline & \multicolumn{2}{c}{ Spearman correlations* } \\
& A.funestus & A. gambiae s.l. \\
\hline Trophozoite positivity & -0.15 & $0 \cdot 11$ \\
& $(0.2)$ & $(0 \cdot 3)$ \\
Gametocyte positivity & -0.01 & -0.07 \\
& $(0 \cdot 9)$ & $(0 \cdot 5)$ \\
Density of trophozoites & -0.14 & $-0 \cdot 15$ \\
(positives only) & $(0.3)$ & $(0 \cdot 2)$ \\
Density of gametocytes & 0.24 & 0.39 \\
(positives only) & $(0.3)$ & $(0 \cdot 2)$ \\
Total mosquitoes & 735 & 622 \\
examined & & \\
\hline
\end{tabular}

* Figures in parentheses are $P$-values. Results refer to 140 paired slides and mosquito collections.

\section{DISCUSSION}

The detection of oocysts in mosquitoes caught in nets-with-holes placed over known hosts represents a straightforward means of studying the infectiousness of individual humans. In Method I, mosquitoes were held for 5-7 days, resulting in large oocysts which could easily be detected. The principal difficulty in this method arises from uncertainties in the origins of infections in the mosquitoes, some of which may have developed from bloodmeals taken prior to the recent one. This uncertainty was minimized by using Method II since oocysts resulting from the experimental bloodmeal could generally be distinguished by size from older oocysts (Shute $\&$ Maryon, 1951; Muirhead-Thomson, 1957; Haji et al. 1996).

Petraca \& Beier (1992) found that $A$.gambiae from Kisumu, Kenya, with the standard $2 \mathrm{~L}$ karyotype were more than twice as likely to be infected with $P$. falciparum sporozoites as carriers of the inverted karyotype. However, Lines, Wilkes \& Lyimo (1991) found that almost all $A$. gambiae eventually acquired infections as they aged suggesting that there was little or no genetic refractoriness to infection with $P$. falciparum. Whilst the population in Kisigese may be structured into more and less susceptible mosquitoes we have no evidence that this is the case. Changes in the population structure are unlikely to be the explanation for lower oocyst rates in the second part of the study when Method II was adopted. When mosquitoes are examined on day 3 only, some oocysts might have not yet become patent (Haji et al. 1996). 
In our study $A$. gambiae s.1. and $A$. funestus were collected together from 84 of the 107 nets. There was no significant difference in overall oocyst rates observed in the two species from these collections (8.0\% and $7.6 \%$ in $A$. funestus and $A$. gambiae respectively), and there were strong correlations between the oocyst rates in the two species when they fed on the same individuals. In one case we found that 18 out of $19(95 \%)$ of the A. funestus available for dissection, after feeding on a 3 -year-old boy, were infected (determined by Method II). Thus our data suggest that both $A$. funestus and $A$. gambiae are completely susceptible to infection by $P$. falciparum. In this study there were no consistent differences between the two species in apparent susceptibility.

Although the two different oocyst rate determination methods were applied during different time periods, temporal fluctuations in infectivity of the host population probably do not account for much of the difference in results using the two methods. The fluctuations in oocyst prevalence observed at different seasons did not show any obvious pattern in relation to gametocyte rate.

It would appear that the main factors that governed host infectiousness in this sample changed rather irregularly throughout the study. However, we did not succeed in identifying any host factors which had a substantial effect on the likelihood of the mosquito developing oocysts in this area of very high malaria endemicity. All oocyst infections in mosquitoes must result from a bloodmeal in which at least 1 male and 1 female viable gametocyte was imbibed but, in keeping with Muirhead-Thomson (1954), we found that cryptic gametocytaemia resulted in mosquito infections and oocyst rates in the mosquitoes that were similar regardless of whether gametocytes or trophozoites were detected in the human host. Oocyst rates also showed only a weak relationship with gametocyte densities in contrast to other studies which have found associations between gametocyte density and infectiousness (Draper, 1953; Tchuinkam et al. 1993).

Gametocytaemia was strongly negatively correlated with age. Consistent with other studies it declined more steeply with age than did asexualstage parasite rates (Muirhead-Thomson, 1954; Graves et al. 1988; Molineaux \& Gramiccia 1980). However, this decline in gametocyte rate was not matched by a decline in infectiousness of the host to mosquitoes. This is consistent with the weak relationship which we found between patent gametocytaemia and infectiousness. Other studies have also reported a weak age dependence in the infectiousness of the human host to mosquitoes (e.g. MuirheadThomson \& Mercier, 1952). The absence of a relationship between gametocyte density and host infectiousness indicates that other factors override the effect of gametocyte density on infectiousness.
These may include variations in the infectivity of the gametocytes and effects of transmission blocking immunity.

We thank the villagers of Kisegese for their participation in this study. Thanks to the field assistants, Anniseth Kihonda, Kanisius Mserenge and Romanus Ndunguru, for collecting and dissecting the mosquitoes. We also received generous help from the technical staff of the entomology unit of the Microbiology Department, Nijmegen University; from Marcel Tanner, Wen Kilama (Director General, National Institute of Medical Research, Tanzania), and from Robert Sauerwein. This study was part of the Kilombero Malaria Project, which was conducted at the Ifakara Centre in collaboration with the Tanzania National Institute of Medical Research (NIMR), the Swiss Tropical Institute (Switzerland), Imperial College (England), the Universities of Wageningen and Nijmegen (The Netherlands) and the World Health Organization Immunology Research Training Centre, Geneva (Switzerland). Funds for this component of the project were provided by the Directorate General of Development Cooperation DGIS (NL 002701) of the Dutch Government and the Rudolf Geigy Foundation. Research Clearance was granted by the Tanzania Commission for Science and Technology as per ref NSR/RCA 90.

\section{REFERENCES}

CHARLWOOD, J. D., KIHONDA, J., SAMA, S., BILLINGSLEY, P. F., HADJI, H., VERhaVE, J. P., LYiMo, E. \& SMITH, T. (1995a). The rise and fall of Anopheles gambiae in a Tanzanian village. Bulletin of Entomological Research 85, 37-44.

CHARLWOOD, J. D., SMITH, T., KIHONDA, J., HEIZ, B., Bi llingsley, P. F. \& TAKken, w. (1995 b). Density independent feeding success in malaria vectors from Tanzania. Bulletin of Entomological Research 85, 29-35.

DEARSLY, A. L., SINDEN, R. E. \& SELF, I. A. (1990). Sexual development in malaria parasites: gametocyte production, fertility and infectivity to mosquitoes. Parasitology 100, 359-368.

DRA PER, C. C. (1953). Observations on the infectiousness of gametocytes in hyperendemic malaria. Transactions of the Royal Society of Tropical Medicine and Hygiene 47, $160-165$.

GAMAGE-MENDis, A. C., RAJAKARUNA, J., CARTER, R. \& MENDIS, K. N. (1991). Infectious reservoir of Plasmodium vivax and Plasmodium falciparum malaria in an endemic region of Sri Lanka. American Fournal of Tropical Medicine and Hygiene 45, 479-487.

GITHEKO, A. K., BRANDLING-BENNET, A. D., BEIER, M., A TIELI, F., OWAGA, M. \& COlliNS, F. H. (1992). The reservoir of Plasmodium falciparum malaria in a holoendemic area of western Kenya. Transactions of the Royal Society of Tropical Medicine and Hygiene 86, 355-358.

GRAVES, P. M., BURKOT, T. R., CARTER, R., CATTANI, J. A., LAGOG, M., PARKER, J., BRABIN, B. J., GIBSON, F. D., BRADLEY, D. J. \& ALPERS, M. P. (1988). Measurement of malaria infectivity of human populations to mosquitoes in the Madang area, Papua New Guinea. Parasitology 97, 251-263. 
GRAVES, P. M., BURKoT, T. R., SAUL, A. J., HAYES, R. J. \& CARTER, R. (1990). Estimation of Anopheline survival rate, vectorial capacity and mosquito infection probability from malaria vector infection rates in villages near Madang, Papua New Guinea. Fournal of Applied Ecology 27, 134-147.

LINES, J. D., WILKES, T. J. \& LYIMO, E. O. (1991). Human malaria infectiousness measured by age-specific sporozoite rates in Anopheles gambiae in Tanzania. Parasitology 102, 167-177.

MEUWISSEN, J. H. (1990). Current studies related to the development of transmission-blocking malaria vaccines: a review. Transactions of the Royal Society of Tropical Medicine and Hygiene 83 (Suppl.) 57-60.

Molineaux, L. \& GRAmiccia, G. (1980). The Garki Project. World Health Organization, Geneva.

MUIRHEAD-THOMSON, R. C. (1954). Factors determining the true reservoir of Plasmodium falciparum and Wuchereria bancrofti in a West African Village. Transactions of the Royal Society of Tropical Medicine and Hygiene 48, 208-225.

Muirhead-THomson, R. C. (1957). Notes on the characters of Plasmodium malariae oocysts of possible value in mixed infections. American Fournal of Tropical Medicine and Hygiene 6, 980-985.
MUIRHEAD-THOMSON, R. C. \& MERCIER, E. C. (1952).

Factors in malaria transmission in Anopheles albimanus in Jamaica. Annals of Tropical Medicine and Parasitology 46, 103-116.

PETRACA, v. \& BEIER, J. c. (1992). Intraspecific chromosomal polymorphism in the Anopheles gambiae complex as a factor affecting malaria transmission in the Kisumu area of Kenya. American Fournal of Tropical Medicine and Hygiene 46, 229-237.

SHUTE, P. G. \& MARYON, M. (1952). A study on human malaria oocysts as an aid to species diagnosis. Transactions of the Royal Society of Tropical Medicine and Hygiene 46, 275-292.

SMITH, T., CHARLWOOD, J. D., KIHONDA, J., MWANKUSYE, S., BILLINGSLEY, P., MEUWISSEN, J., LYIMO, E., TAKKEN, W., TEUSCHER, T. \& TANNER, M. (1993). Absence of seasonal variation in malaria parasitaemia in an area of intense seasonal transmission. Acta Tropica 54, 55-72.

TCHUINKAM, T., MULDER, B., DECHERING, K., STOFFELS, H., VERHAVE, J.-P., COT, M., CARNEVALE, P., MEUWISSEN, J.H.E.Th. \& ROBERT, V. (1993). Experimental infections of Anopheles gambiae with Plasmodium falciparum of naturally infected gametocyte carriers in Cameroon : factors influencing the infectivity to mosquitoes. Tropical Medicine and Parasitology 44, 271-276. 